\title{
Dihydroartemisinin attenuates benign prostatic hyperplasia in rats by inhibiting prostatic epithelial cell proliferation
}

\author{
Bo Zhang, Xiang Chen, Yu Gan, Bing-Sheng Li, Kang-Ning Wang, Yao He \\ Department of Urology, Xiangya Hospital, Central South University, Changsha, China \\ Contributions: (I) Conception and design: B Zhang, Y He; (II) Administrative support: None; (III) Provision of study materials or patients: X Chen, \\ Y He; (IV) Collection and assembly of data: B Zhang, Y He, G Yu, BS Li, KN Wang; (V) Data analysis and interpretation: B Zhang, Y He; (VI) \\ Manuscript writing: All authors; (VII) Final approval of manuscript: All authors. \\ Correspondence to: Yao He. Department of Urology, Xiangya Hospital, Central South University, Xiangya Road 88, Changsha 410008, China. \\ Email: heyao1984@163.com.
}

Background: Benign prostatic hyperplasia (BPH) is a common urological condition in aging men. While dihydroartemisinin (DHA) exhibits a wide range of pharmacological activities, to date, there have been no studies examining the effects of DHA on BPH.

Methods: An in vivo BPH model was constructed in rats via daily subcutaneous injection of testosterone propionate (TP) for 28 consecutive days. Rats were randomly distributed into four groups and treated as follows: (I) control; (II) TP treatment; (III) TP and finasteride treatment (positive control); and (IV) TP and DHA treatment. At the end of the experiment, rats were sacrificed and the prostate weight, prostate index, thickness of the epithelium, collagen deposition, serum dihydrotestosterone (DHT) levels, $5 \alpha$-reductase 2 (5AR-2) expression, and proliferating cell nuclear antigen (PCNA) levels in the prostate were examined. Normal human prostatic epithelial RWPE-1 cells were used in in vitro experiments to further investigate the anti-proliferative effects of DHA.

Results: TP increased the prostate weight and prostate index in rats, and this effect was reduced with DHA treatment. In addition, DHA attenuated the morphological changes and collagen deposition in the prostate tissue induced by TP. Furthermore, DHA reduced the expression of PCNA, serum DHT, and prostatic 5AR-2 in rats with TP-induced BPH. In vitro analysis revealed that DHA significantly inhibited the proliferation of TP-treated RWPE-1 cells.

Conclusions: DHA significantly inhibited the development of BPH by suppressing serum DHT levels, prostatic 5AR-2 expression, and the proliferation of benign prostatic epithelial cells. Thus, DHA is a novel medicinal agent with potential therapeutic efficacy in the treatment of patients with BPH.

Keywords: Benign prostatic hyperplasia (BPH); testosterone propionate (TP); dihydroartemisinin (DHA); proliferation

Submitted Jun 04, 2021. Accepted for publication Jul 23, 2021.

doi: $10.21037 / \mathrm{atm}-21-3296$

View this article at: https://dx.doi.org/10.21037/atm-21-3296

\section{Introduction}

Benign prostatic hyperplasia (BPH) is an age-related urological condition and its incidence increases gradually with age (1). Approximately $50 \%$ of men at the age of 60 will experience $\mathrm{BPH}$ symptoms, and the prevalence of these symptoms increases to $80 \%$ in patients over 70 years of age $(2,3)$. BPH is a worldwide health concern and represents a rapidly growing societal financial burden (4). BPH can progressively lead to distressing lower urinary tract symptoms (LUTS), including storage and voiding inadequacies (5). While the specific molecular and cellular mechanisms underlying BPH pathogenesis are not fully understood, numerous studies have suggested that androgenmediated stimulation of prostatic cellular proliferation may 
play a role in the development of $\mathrm{BPH}(6,7)$.

Dihydrotestosterone (DHT), converted from testosterone by the enzyme $5 \alpha$-reductase ( $5 \mathrm{AR}$ ), may be a crucial factor in prostatic epithelial cell proliferation and function $(8,9)$. Current drug treatments for BPH include $5 \alpha$-reductase inhibitors (5ARIs) and $\alpha$-blockers $(10,11)$ such as tamsulosin, alfuzosin, and doxazosin, which can relax the smooth muscles of the prostate and bladder neck (12). However, these do not reduce the volume of the enlarged prostate. $5 \mathrm{ARIs}$, such as finasteride and dutasteride, can inhibit the development of DHT and reduce the risk of acute urinary retention and surgical intervention. While both antagonists are effective at treating $\mathrm{BPH}$, these drugs have many adverse events, including abnormal ejaculation, erectile dysfunction, and gynecomastia (13). Therefore, the development of treatment options with fewer adverse effects is warranted.

Dihydroartemisinin (DHA) is the primary active product of artemisinin, and has been used as a safe and effective drug for malaria treatment for many years (14). Numerous studies have shown that DHA has anti-tumor, antifibrotic, anti-inflammatory, and anti-bacterial properties $(15-17)$. In addition, some studies have demonstrated that DHA can inhibit cell proliferation with minimal effects on normal cells. Yuan et al. found that DHA inhibited the proliferation and colony formation ability of lung cancer cells and promoted their death (18). Our previous study showed that DHA attenuates renal fibrosis by inhibiting the proliferation and differentiation of fibroblasts (16). Yu et al. demonstrated that DHA effectively inhibits hypoxiainduced increases in cell proliferation, migration, and oxidative stress in pulmonary artery endothelial cells (19). Furthermore, Dong et al. showed that DHA inhibits human umbilical vein endothelial cell proliferation by suppressing the ERK signaling pathway (20).

Since targeting cellular proliferation is crucial in the prevention of $\mathrm{BPH}$ progression, DHA may be a potential treatment option. Therefore, this study explored the antiproliferative effects of DHA on testosterone propionate (TP)-induced $\mathrm{BPH}$ in vivo using rats and in vitro using TPstimulated prostatic epithelial cells. We present the following article in accordance with the ARRIVE reporting checklist (available at https://dx.doi.org/10.21037/atm-21-3296).

\section{Methods}

\section{Drugs}

TP (98\% purity) and DHA $\left(\mathrm{C}_{15} \mathrm{H}_{24} \mathrm{O}_{5},>98 \%\right.$ purity) were purchased from Macklin Biochemical Co., Ltd. (Shanghai, China). Finasteride (Fin) $\left(\mathrm{C}_{23} \mathrm{H}_{36} \mathrm{~N}_{2} \mathrm{O}_{2}, 99.97 \%\right.$ purity) was used as a positive control, and was obtained from MedChemExpress (Monmouth Junction, NJ, USA).

\section{Animals and treatment}

Twenty 10 -week-old male Sprague-Dawley rats were provided by the Laboratory Animal Unit (Central South University, China). The rats were acclimatized in a $12 / 12$ hour light/dark cycle and temperature controlled (23$25^{\circ} \mathrm{C}$ ) room for 1 week prior to the experiments. The rats were randomly distributed into the following four groups: (I) control; (II) TP; (III) TP + finasteride (Fin: $10 \mathrm{mg} / \mathrm{kg} /$ day; p.o.); and (IV) TP + DHA (DHA: $40 \mathrm{mg} / \mathrm{kg} /$ day; p.o.). Rats in the 3 experimental groups were treated with subcutaneous injections of TP ( $3 \mathrm{mg} / \mathrm{kg} /$ day) for 4 weeks to induced BPH. Rats in the control group were injected with olive oil instead of TP. After 4 weeks, rats were sacrificed and blood samples were collected from the caudal vena cava. Blood samples were centrifuged at $1,500 \times \mathrm{g}$ for 10 minutes at $4{ }^{\circ} \mathrm{C}$ and the serum was collected. The prostate tissues were harvested immediately and weighed. One part of prostate tissue was fixed in a $4 \%$ paraformaldehyde solution, and the remaining tissue was stored at $-80{ }^{\circ} \mathrm{C}$ for further analysis. A protocol was prepared before the study without registration. Experiments were performed under a project license (No.: 201703545) granted by Central South University Science Research Center (Changsha, China), in compliance with the National Institutes of Health guidelines for the Care and Use of Laboratory Animals.

\section{Prostate index}

The prostate index was calculated as the ratio of the prostate weight $(\mathrm{mg})$ to the body weight $(100 \mathrm{~g})$.

\section{Histological analyses}

The prostate tissue was embedded in paraffin and cut into 4-micrometer sections. Hematoxylin and eosin (H\&E) staining and Masson's trichrome staining were performed as previously described (16). Images of the H\&E and Masson's trichrome-stained sections were acquired using a microscope (Nikon, Japan). The thickness of the epithelium in the prostate tissue (TETP) was measured using Leica Application Suite (ver. 3.3.0) software. The percentage area 
of collagen fibers was quantified from three random fields of view at 100x magnification from each tissue slice and quantified with Image Pro Plus 6.0 software.

\section{Immunobistochemistry}

The sections were deparaffinized in xylene, rehydrated using descending grades of alcohol, and immersed in 3\% hydrogen peroxide to inactivate endogenous peroxidase. The cells were then incubated in a blocking buffer containing $5 \%$ bovine serum albumin for 1 hour. The sections were incubated at $4{ }^{\circ} \mathrm{C}$ overnight with antibodies against proliferating cell nuclear antigen (PCNA; 1:100; Servicebio, China) followed by incubation with a 1:500 dilution of horseradish peroxidase (HRP)-conjugated antirabbit secondary antibody (1:100; Sigma-Aldrich, St. Louis, $\mathrm{MO}, \mathrm{USA})$ at room temperature for 30 minutes. Images were acquired using a microscope (Nikon).

\section{Serum concentrations of $\mathrm{DHT}$}

Quantification of DHT in the serum was determined using an enzyme-linked immunosorbent assay (ELISA) kit (BioLegend, Inc.) according to the manufacturer's instructions.

\section{Cell culture}

The RWPE-1 human prostatic epithelial cell line was purchased from Procell Life Science \& Technology Co., Ltd. (Wuhan, China). RWPE-1 cells were maintained at $37{ }^{\circ} \mathrm{C}$ in Roswell Park Memorial Institute (RPMI)-1640 medium (Gibco, Big Cabin, OK, USA) supplemented with $1 \%$ penicillin/streptomycin and $10 \%$ fetal bovine serum (Sigma-Aldrich Inc.) in a humidified atmosphere containing $5 \% \mathrm{CO}_{2}$. The cells were treated with $0.5 \mu \mathrm{M}$ TP to induce cell proliferation in the presence or absence of finasteride $(0.5 \mu \mathrm{M})$ or DHA $(30 \mu \mathrm{M})$.

\section{Cell viability assays}

RWPE-1 cells were seeded into 96-well plates. The Cell Counting Kit-8 (CCK-8; Dojindo, Japan) was used to assess proliferation of RWPE-1 cell according to the manufacturer's instructions.

\section{EdU proliferation assay}

EdU staining is a sensitive and robust method for the detection and quantification of cell proliferation (21). An EdU assay was performed according to the manufacturer's instructions (Click-iT EdU Kit, Invitrogen, Waltham, MA, USA). Samples were analyzed using the iRiS Digital Cell Imaging System (Logos Biosystems, Anyang, Korea).

\section{Western blot analyses}

Prostate tissues were minced and lysed with RIPA buffer (Beyotime Biotechnology, China). Equivalent amounts of protein samples were separated by sodium dodecylsulfatepolyacrilamide gel electrophoresis and transferred to polyvinylidene difluoride membranes (Millipore, USA). The membranes were blocked using $5 \%$ fat-free milk and incubated with primary antibodies against glyceraldehyde 3-phosphate dehydrogenase (GAPDH, 1:2,000; Servicebio), PCNA (1:500; Servicebio), and 5AR-2 (1:500; Abcam Inc.) overnight at $4{ }^{\circ} \mathrm{C}$. Following washing, membranes were incubated with HRP-conjugated secondary antibodies at room temperature for 2 hours. The chemiluminescent intensities were quantified using Image $\mathrm{J}$ and normalized to GAPDH.

\section{Statistical analysis}

The results are presented as mean \pm standard deviation (SD). Statistical analyses were performed using GraphPad Prism 8.0. Statistical significance for comparisons among two groups was analyzed using the $t$-test. A P value $<0.05$ was considered statistically significant.

\section{Results}

\section{$D H A$ attenuates prostate weight and index in the $\mathrm{BPH}$ rat model}

Figure $1 A$ shows the chemical structure of DHA. The prostate index is commonly used to assess the degree of $\mathrm{BPH}$ development (22). The prostate weight of rats in the TP-induced $\mathrm{BPH}$ group $(1,908.3 \pm 125.6 \mathrm{mg})$ was significantly higher than that of rats in the control group $(989.3 \pm 81.0 \mathrm{mg})(\mathrm{P}<0.01)$ (Figure $1 B)$. However, treatment with Fin $(1,382.3 \pm 310.8 \mathrm{mg})$ and DHA $(1,480.0 \pm 127.5 \mathrm{mg})$ 

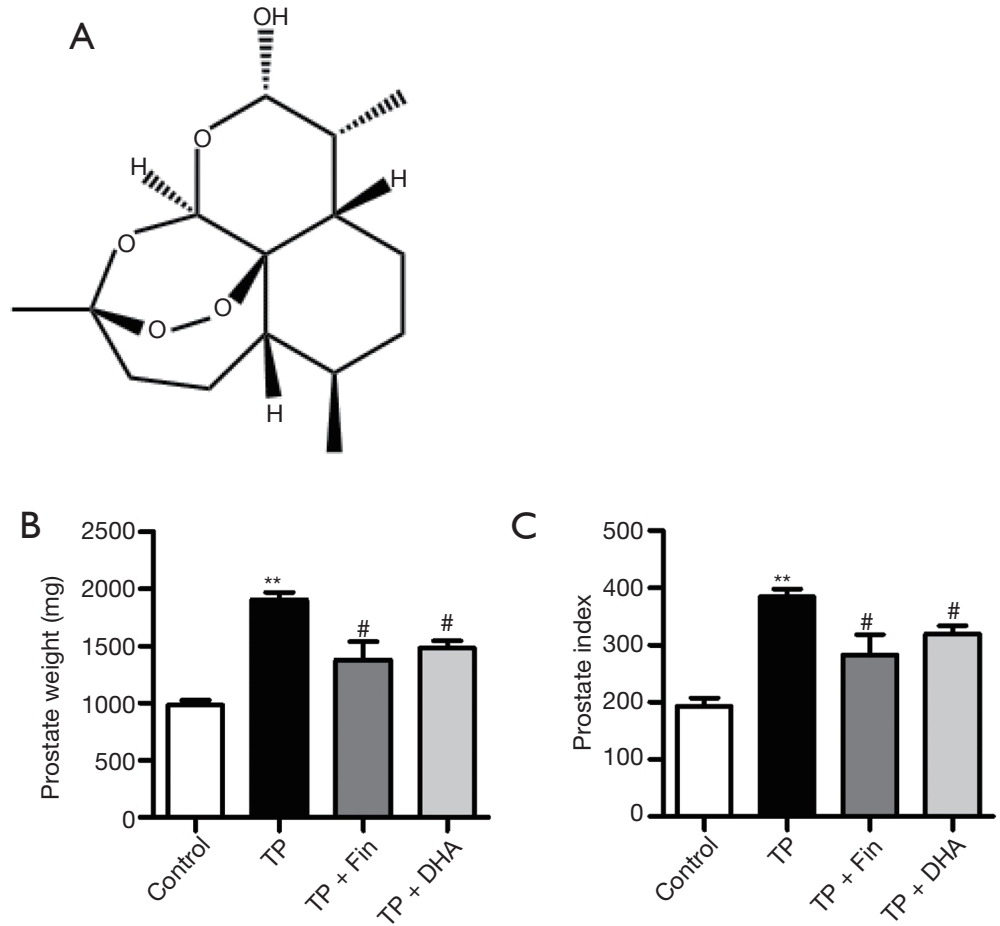

Figure 1 The effects of dihydroartemisinin on prostate weight and prostate index in rats. (A) The chemical structure of DHA. (B) The total prostate weight of the rats. (C) The ratio of prostate weight $(\mathrm{mg})$ to body weight $(100 \mathrm{~g})$. $\mathrm{n}=4$; ${ }^{* *} \mathrm{P}<0.01$ versus Control group; ${ }^{\mathrm{P}}<0.05 \mathrm{versus}$ TP group. DHA, dihydroartemisinin; TP, testosterone propionate.

significantly reduced the prostate weight compared to that observed in untreated BPH rats (Figure 1B). Moreover, the prostate weight/body weight ratio or the prostate index was significantly higher in the untreated BPH rats $(384.8 \pm 26.1)$ compared to BPH rats treated with Fin $(282.8 \pm 71.2)$ and DHA (319.3 \pm 29.3$)$ (Figure 1C).

\section{$\mathrm{DH} A$ alleviates the histological changes and collagen deposition associated with the BPH rat model}

The effects of DHA on prostate gland morphology were investigated by histological examination of the prostate and collagen deposition in the tissue. H\&E staining showed that rats treated with $3 \mathrm{mg} / \mathrm{kg} /$ day TP for 28 days exhibited typical patterns of glandular hyperplasia with concomitant papillary in folding and stacking of epithelial cells, a vacuolated cytoplasm pointing towards the glandular lumen, and a reduced glandular luminal area. Administration of Fin and DHA for 28 days alleviated these typical hyperplastic patterns (Figure 2A). In addition, as shown in Figure 2B, rats in the TP group showed a significant increase $(60.7 \pm 15.0 \mu \mathrm{m})$ in TETP compared to the normal rats $(14.0 \pm 5.2 \mu \mathrm{m})$. Rats in the Fin- $(30.8 \pm 38.5 \mu \mathrm{m})$ and DHA-treated $(37.4 \pm 11.7 \mu \mathrm{m})$ groups showed a significant reduction in prostate thickness.

Extracellular matrix deposition is a salient feature of BPH (23). As shown in Figure 2A, collagen deposition was not observed in the interstitial tissues of control rats, whereas collagen deposition was noticeable in TP rats, as visualized by Masson's trichrome staining. Compared to $\mathrm{TP}$ rats, prostate tissues in the $\mathrm{TP}+$ Fin and $\mathrm{TP}+$ DHA rats showed reduced areas of collagen deposition (Figure $2 \mathrm{~A}, 2 \mathrm{C}$ ). These results demonstrated that DHA alleviated the histological changes and collagen deposition associated with the BPH rat model.

\section{DHA reduces the expression of prostatic proliferation markers in the prostate tissues of $\mathrm{BPH}$ rats}

PCNA is widely used to evaluate cellular proliferation (24). Immunohistochemical staining showed that the expression of PCNA was significantly increased after TP treatment (Figure $3 A$ ). In the $\mathrm{TP}+$ Fin and $\mathrm{TP}+\mathrm{DHA}$ groups, PCNA expression was significantly lower than that in the TP group. Western blot analysis showed that TP treatment 

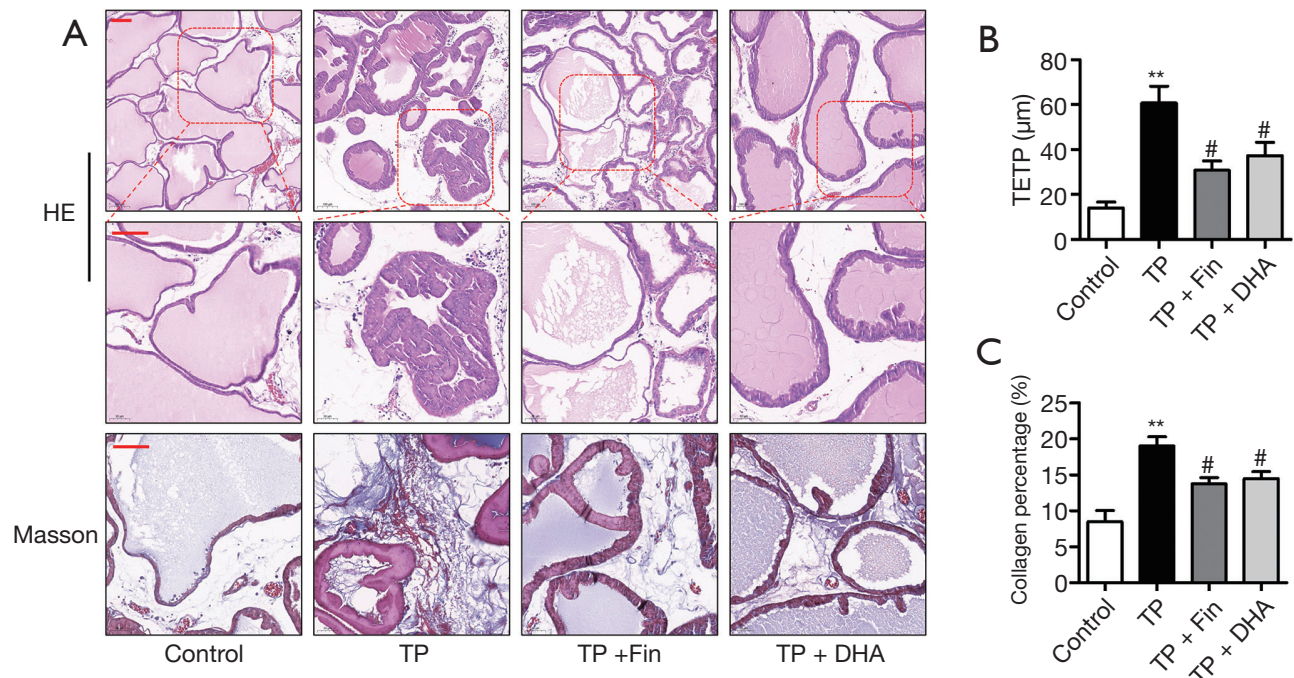

Figure 2 The effects of dihydroartemisinin on the histological changes and collagen deposition in rats. (A) H\&E staining of prostate tissues (top panel: $100 \times$ magnification, bar $=50 \mu \mathrm{m}$; second panel: $200 \times$ magnification, bar $=50 \mu \mathrm{m}$ ). Masson's trichrome staining of prostate tissues (third panel: $200 \times$ magnification, bar $=50 \mu \mathrm{m})$. (B) The thickness of epithelium tissue from prostate $(T E T P)\left(n=4 ;{ }^{* *} \mathrm{P}<0.01\right.$ versus Control group; ${ }^{~} \mathrm{P}<0.05$ versus TP group). (C) Quantification of Masson's trichrome staining. The percentage area of collagen fiber was quantified from three random fields of view $\left(200 \times\right.$ magnification) from each tissue slices $\left(\mathrm{n}=4 ;{ }^{* *} \mathrm{P}<0.01\right.$ versus Control group; ${ }^{*} \mathrm{P}<0.05$ versus $\mathrm{TP}$ group). H\&E, hematoxylin and eosin; DHA, dihydroartemisinin; TP, testosterone propionate.

induced a significant upregulation of PCNA expression compared to control rats. However, the upregulated PCNA expression was alleviated in the $\mathrm{TP}+\mathrm{Fin}$ and $\mathrm{TP}+\mathrm{DHA}$ groups (Figure 3B). These results indicated that DHA reduced the expression of prostatic proliferation markers in the prostate tissues of $\mathrm{BPH}$ rats.

\section{DHA suppresses serum DHT levels and prostatic $5 \alpha$-reductase 2 expression in BPH rats}

DHT is one of the most crucial factors in prostatic epithelial cell proliferation (25). ELISA assays demonstrated that the serum levels of DHT were significantly higher in TP rats compared to control rats (Figure 4A). Intervention with Fin and DHA significantly decreased serum DHT levels. The conversion of testosterone to DHT occurs by the action of the enzyme $5 \mathrm{AR}(8,9)$. Western blot analyses showed that expression of 5AR-2 in the TP group was higher than that in the normal control group (Figure 4B). Treatment with Fin and DHA resulted in the inhibition of 5AR-2 expression in TP-treated rats.

\section{DHA mitigates the proliferation of TP-induced RWPE-1 cells in vitro}

Human RWPE-1 prostatic epithelial cells were used to explore the anti-proliferative effect of DHA in vitro. The CCK-8 assay showed that $100 \mu \mathrm{M}$ DHA significantly decreased RWPE-1 cell viability. A lower concentration of $30 \mu \mathrm{M}$ DHA had no marked deleterious effects on the cells and was thus used for further experiments (Figure $5 A$ ). The EdU assays demonstrated that $0.5 \mu \mathrm{M}$ TP enhanced cell proliferation compared to untreated control cells. However, Fin and DHA significantly reduced cell proliferation in the TP-treated cells (Figure 5B,5C).

\section{Discussion}

The present study explored the effects of DHA on TPinduced $\mathrm{BPH}$ in rats. DHA administration for 4 weeks significantly attenuated the TP-induced increase in prostate weight and index, changes in the histology of prostate tissue, and collagen deposition, by decreasing serum DHT and prostatic 5AR-2 expression. In addition, DHA inhibited the 
A PCNA

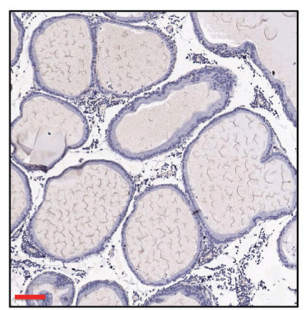

Control

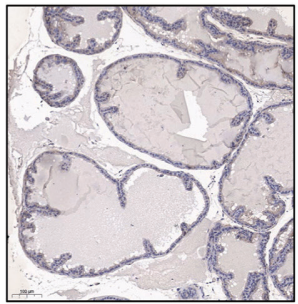

$\mathrm{TP}+$ Fin

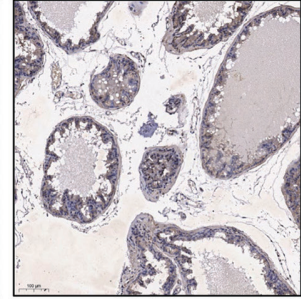

TP

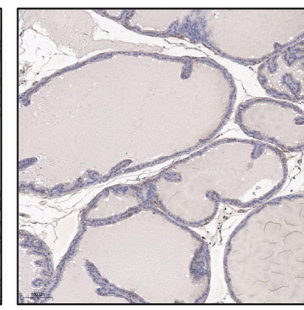

$\mathrm{TP}+\mathrm{DHA}$
B
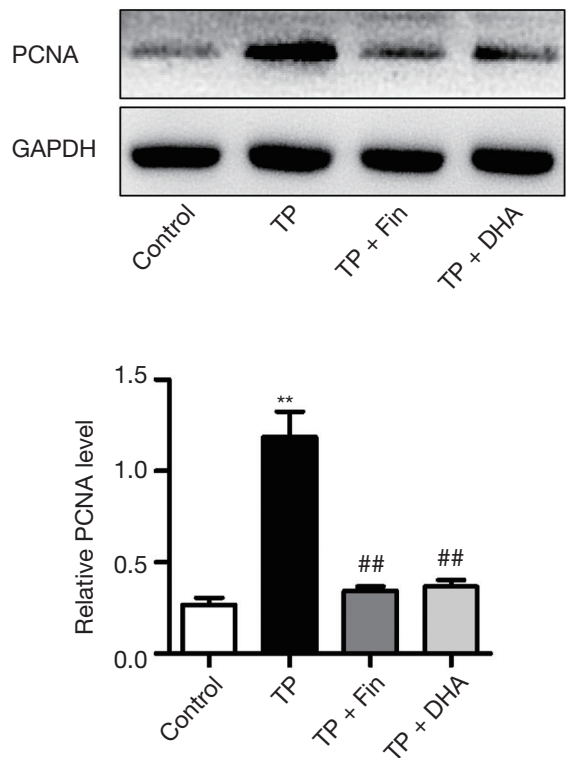

Figure 3 The effects of dihydroartemisinin on proliferating cell nuclear antigen expression in the prostate tissues. (A) Immunohistochemical staining of PCNA $(100 \times$ magnification, bar $=50 \mu \mathrm{m})$. (B) Protein expression of PCNA in prostate tissues of rats detected by western blotting $\left(\mathrm{n}=3 ;{ }^{* *} \mathrm{P}<0.01\right.$ vs. Control group; ${ }^{\# \#} \mathrm{P}<0.01$ vs. TP group). DHA, dihydroartemisinin; TP, testosterone propionate; PCNA, proliferating cell nuclear antigen.

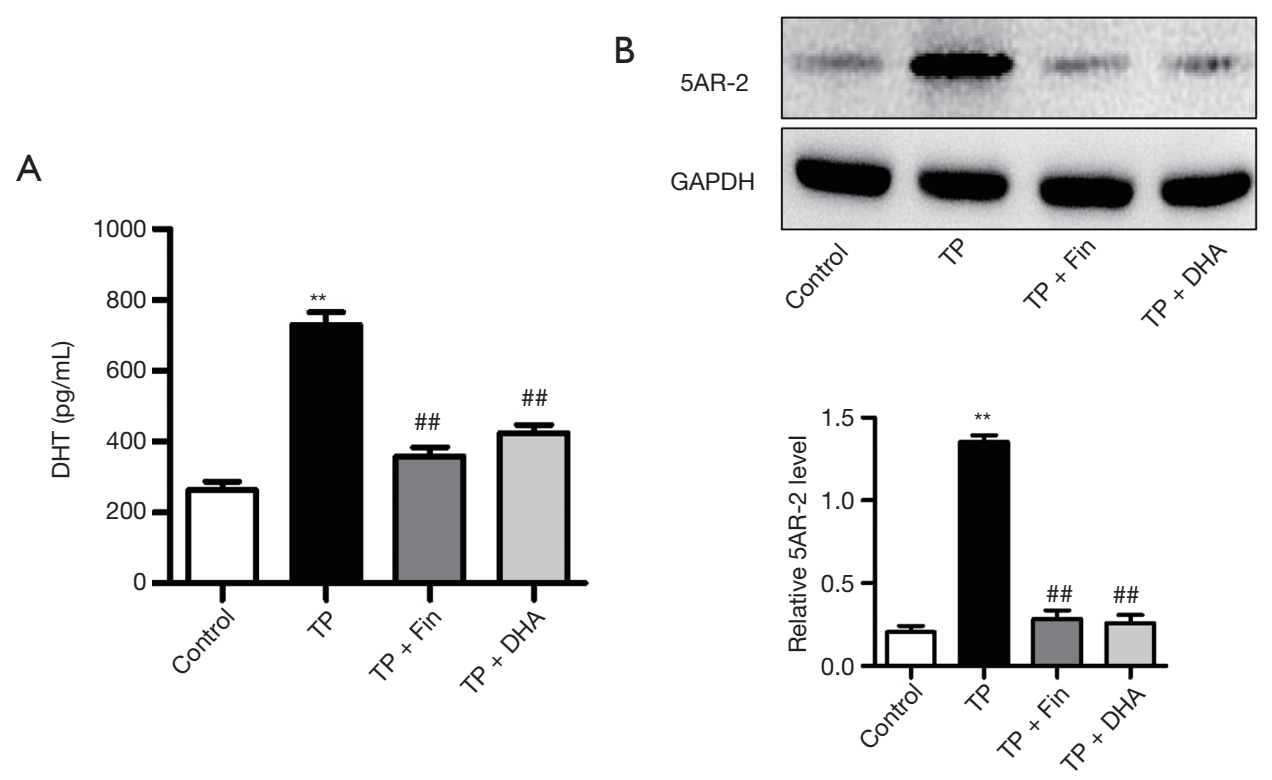

Figure 4 The effects of dihydroartemisinin on dihydrotestosterone and $5 \alpha$-reductase 2 expression in rats. (A) DHT levels were quantified by serum rat ELISA assay. (B) Protein expression of 5AR-2 in prostate tissues of rats detected by western blotting ( $\mathrm{n}=3$; ${ }^{* *} \mathrm{P}<0.01$ vs. Control group; ${ }^{\#} \mathrm{P}<0.01$ vs. TP group). DHA, dihydroartemisinin; TP, testosterone propionate; DHT, dihydrotestosterone; $5 \mathrm{AR}-2,5 \alpha-$ reductase 2 . 
A

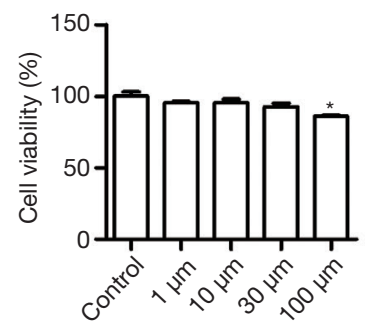

C

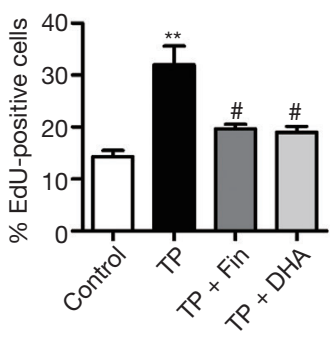

B
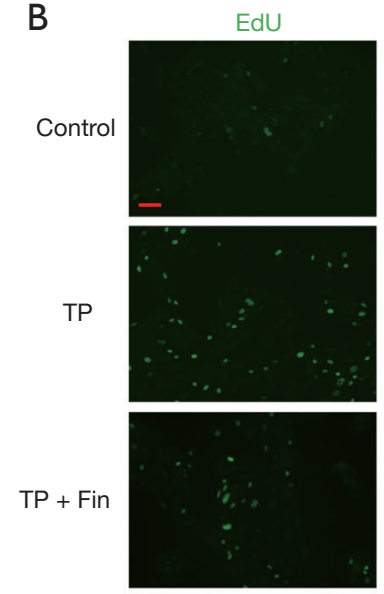

TP + DHA

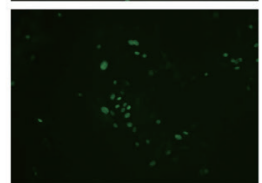

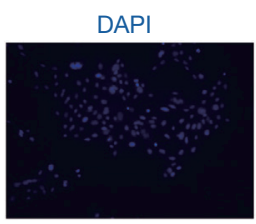
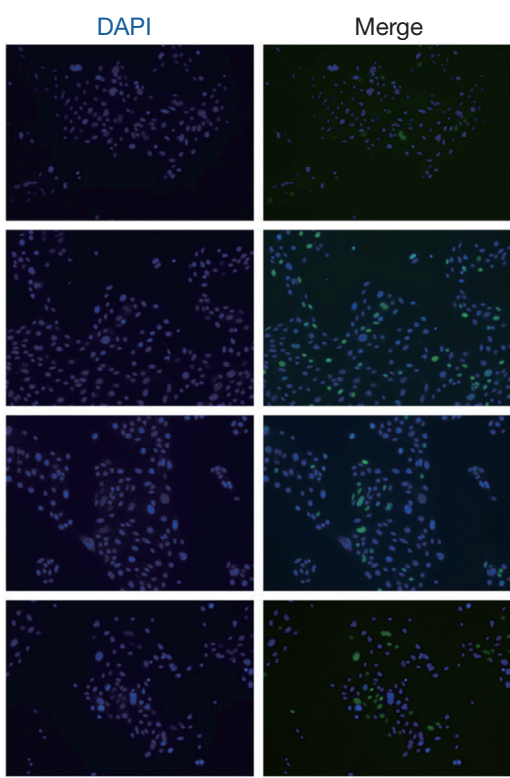

Figure 5 The effects of dihydroartemisinin on proliferation of RWPE-1 cells in vitro. (A) Cell viability was evaluated by the CCK-8 assay ( $\mathrm{n}=3 ;{ }^{*} \mathrm{P}<0.05$ vs. Control group). (B) EdU-incorporated cells were detected by immunofluorescence (100× magnification, bar $=50$ um). (C) Quantification of EdU-positive cells, based on the percentage of nuclei stained with $\mathrm{EdU}\left(\mathrm{n}=3 ;{ }^{* *} \mathrm{P}<0.01\right.$ vs. Control group, ${ }^{\#} \mathrm{P}<0.05$ vs. TP group). DHA, dihydroartemisinin; TP, testosterone propionate; CCK-8, cell-counting kit 8.

proliferation of prostatic epithelial cells in vivo and in vitro.

$\mathrm{BPH}$ is one of the most common benign proliferative diseases in the urinary system of middle-aged and elderly men. Despite its high prevalence and adverse socioeconomic impact, the pathophysiology underlying the development of $\mathrm{BPH}$ is complicated and poorly understood. The occurrence of $\mathrm{BPH}$ is associated with the induction of the proliferation of both epithelial and stromal cells of the prostate in the transitional zone surrounding the urethra (26). PCNA is an essential factor in DNA replication and repair, and is thus widely used to evaluate cell proliferation in benign and malignant proliferating tissues. Furthermore, PCNA levels have been shown to correlate directly with the proliferative state of various tissues, including the prostate $(27,28)$. Consistent with previous studies $(27,28)$, TP-induced BPH in rats was characterized by a significant increase in PCNA expression. However, the oral administration of DHA markedly inhibited PCNA expression. Both CCK-8 and EdU assays demonstrated that DHA prevented the TPinduced cell proliferation in RWPE-1 cells.

Several factors can increase the risk of $\mathrm{BPH}$ development and progression. The dominant roles of the androgen system and aging are clearly recognized (29). Testosterone and DHT are crucial factors for prostatic epithelial cell proliferation and function and are thus involved in the pathogenesis of BPH (9). DHT is a more powerful androgen than testosterone because of its high affinity towards androgen receptors (30). In this study, an in vivo rat model of BPH was constructed by subcutaneous injection of TP (3 mg/kg per day) for 4 weeks. Consistent with previous studies, significant increases in prostate size and weight, and prostate weight to body weight ratio were observed (31); histological microscopic anatomical examination of the prostate showed morphological abnormalities and androgen-stimulated proliferation of prostatic epithelial cells (32). The conversion of testosterone to DHT is facilitated by the enzyme 5AR and DHT production can be inhibited by 5 ARIs (33) such as finasteride, resulting in a decrease in prostate size and BPH-related LUTS (34). The current study demonstrated that prostatic 5AR-2 and serum DHT levels were significantly reduced following treatment with finasteride. Despite its efficacy in the treatment of $\mathrm{BPH}$, long-term use of finasteride has serious adverse effects, including sexual dysfunction, anxiety, depression, memory disturbance, and headaches (35). Consequently, natural plant products have emerged as alternative therapies to inhibit the development of BPH because they have few adverse effects and provide high therapeutic efficacy. 
The Nobel Prize in Physiology or Medicine was awarded to Prof. Youyou Tu for the discovery of artemisinin in 2015. Since artemisinin is hindered by poor water-solubility and low bioavailability, researchers developed a derivative, namely, DHA, which exhibits better bioavailability and improved anti-malarial effects compared to artemisinin (36). Furthermore, DHA has been shown to exert antiproliferative (18-20), anti-fibrotic (16,37), and antiinflammatory activity $(38,39)$.

Extracellular matrix deposition is a salient feature of the benign proliferative disorder BPH. In addition, inflammation has been reported to play a significant role in cell proliferation and the development of $\mathrm{BPH}(5,26)$. Although various studies have investigated the properties of DHA, to date, there have been no studies examining the effects of DHA on BPH. To confirm the anti-BPH effect of DHA, finasteride was used as a positive control. Oral administration of DHA significantly attenuated BPH development with effects comparable to those of finasteride. Furthermore, low-dose DHA had no toxic side effects on RWPE-1 cells and reduced cell proliferation induced by TP. Further studies are warranted to determine the precise mechanisms underlying the anti-proliferative effects of DHA on prostate cells.

In conclusion, this study demonstrated that DHA significantly impeded the development of BPH by suppressing the expression of androgenic hormonerelated markers and inhibiting the proliferation of prostatic epithelial cells. These results suggested that DHA may be a potential therapeutic option for the treatment of patients with BPH.

\section{Acknowledgments}

Funding: This work was supported by grants from the National Natural Science Foundation of China (81700663) and the Natural Science Foundation of Hunan Province (2020JJ5895).

\section{Footnote}

Reporting Checklist: The authors have completed the ARRIVE reporting checklist. Available at https://dx.doi. org/10.21037/atm-21-3296

Data Sharing Statement: Available at https://dx.doi. org/10.21037/atm-21-3296
Conflicts of Interest: All authors have completed the ICMJE uniform disclosure form (available at https://dx.doi. org/10.21037/atm-21-3296). Dr. Zhang and Dr. He reported that this work was supported by grants from the National Natural Science Foundation of China (81700663) and the Natural Science Foundation of Hunan Province (2020JJ5895). The other authors have no conflicts of interest to declare.

Ethical Statement: The authors are accountable for all aspects of the work in ensuring that questions related to the accuracy or integrity of any part of the work are appropriately investigated and resolved. Experiments were performed under a project license (No.: 201703545) granted by Central South University Science Research Center (Changsha, China), in compliance with the National Institutes of Health guidelines for the Care and Use of Laboratory Animals.

Open Access Statement: This is an Open Access article distributed in accordance with the Creative Commons Attribution-NonCommercial-NoDerivs 4.0 International License (CC BY-NC-ND 4.0), which permits the noncommercial replication and distribution of the article with the strict proviso that no changes or edits are made and the original work is properly cited (including links to both the formal publication through the relevant DOI and the license). See: https://creativecommons.org/licenses/by-nc-nd/4.0/.

\section{References}

1. Devlin CM, Simms MS, Maitland NJ. Benign prostatic hyperplasia - what do we know? BJU Int 2021;127:389-99.

2. Clifford GM, Farmer RD. Medical therapy for benign prostatic hyperplasia: a review of the literature. Eur Urol 2000;38:2-19.

3. Wang B, Zhang S, Sun C, et al. Comparison between a transurethral prostate split and transurethral prostate resection for benign prostatic hyperplasia treatment in a small prostate volume: a prospective controlled study. Ann Transl Med 2020;8:1016.

4. Launer BM, McVary KT, Ricke WA, et al. The rising worldwide impact of benign prostatic hyperplasia. BJU Int 2021;127:722-8.

5. De Nunzio C, Salonia A, Gacci M, et al. Inflammation is a target of medical treatment for lower urinary tract symptoms associated with benign prostatic hyperplasia. 
World J Urol 2020;38:2771-9.

6. Yang T, Huang Y, Zhou Y, et al. Simultaneous quantification of oestrogens and androgens in the serum of patients with benign prostatic hyperplasia by liquid chromatography-Tandem mass spectrometry. Andrologia 2020;52:e13611.

7. Tian Y, Liu HM, Yang B, et al. Prostatic anatomical parameters correlate with clinical characteristics suggestive of benign prostatic hyperplasia. Asian J Androl 2021;23:64-8.

8. Jin BR, Kim HJ, Park SK, et al. Anti-Proliferative Effects of HBX-5 on Progression of Benign Prostatic Hyperplasia. Molecules 2018;23:2638.

9. Cha JY, Wee J, Jung J, et al. Anoctamin 1 (TMEM16A) is essential for testosterone-induced prostate hyperplasia. Proc Natl Acad Sci U S A 2015;112:9722-7.

10. Hagberg KW, Divan HA, Nickel JC, et al. Risk of Incident Antidepressant-Treated Depression Associated with Use of 5alpha-Reductase Inhibitors Compared with Use of alpha-Blockers in Men with Benign Prostatic Hyperplasia: A Population-Based Study Using the Clinical Practice Research Datalink. Pharmacotherapy 2017;37:517-27.

11. Sountoulides P, Gravas S. The Impact of Combination Therapy with a-Blockers and 5ARIs on the Progression of BPH. Curr Drug Targets 2015;16:1172-9.

12. Untergasser G, Madersbacher S, Berger P. Benign prostatic hyperplasia: age-related tissue-remodeling. Exp Gerontol 2005;40:121-8.

13. Langan RC. Benign Prostatic Hyperplasia. Prim Care 2019;46:223-32.

14. Keating GM. Dihydroartemisinin/Piperaquine: a review of its use in the treatment of uncomplicated Plasmodium falciparum malaria. Drugs 2012;72:937-61.

15. Pulito C, Strano S, Blandino G. Dihydroartemisinin: from malaria to the treatment of relapsing head and neck cancers. Ann Transl Med 2020;8:612.

16. Zhang B, Liu P, Zhou Y, et al. Dihydroartemisinin attenuates renal fibrosis through regulation of fibroblast proliferation and differentiation. Life Sci 2019;223:29-37.

17. Gutman J, Kovacs S, Dorsey G, et al. Safety, tolerability, and efficacy of repeated doses of dihydroartemisininpiperaquine for prevention and treatment of malaria: a systematic review and meta-analysis. Lancet Infect Dis 2017;17:184-93.

18. Yuan B, Liao F, Shi ZZ, et al. Dihydroartemisinin Inhibits the Proliferation, Colony Formation and Induces Ferroptosis of Lung Cancer Cells by Inhibiting PRIM2/ SLC7A11 Axis. Onco Targets Ther 2020;13:10829-40.
19. Yu H, Liu J, Dong Y, et al. Anti-hypoxic effect of dihydroartemisinin on pulmonary artery endothelial cells. Biochem Biophys Res Commun 2018;506:840-6.

20. Dong F, Tian H, Yan S, et al. Dihydroartemisinin inhibits endothelial cell proliferation through the suppression of the ERK signaling pathway. Int J Mol Med 2015;35:1381-7.

21. Andersen DC, Skovrind I, Christensen ML, et al. Stem cell survival is severely compromised by the thymidineanalog EdU (5-ethynyl-2'-deoxyuridine), an alternative to BrdU for proliferation assays and stem cell tracing. Anal Bioanal Chem 2013;405:9585-91.

22. Madersbacher S, Sampson N, Culig Z. Pathophysiology of Benign Prostatic Hyperplasia and Benign Prostatic Enlargement: A Mini-Review. Gerontology 2019;65:458-64.

23. Elliot SJ, Zorn BH, McLeod DG, et al. Pentosan polysulfate decreases prostate smooth muscle proliferation and extracellular matrix turnover. Prostate Cancer Prostatic Dis 2003;6:138-42.

24. Srinivasan M, Jewell SD. Quantitative estimation of PCNA, c-myc, EGFR and TGF-alpha in oral submucous fibrosis--an immunohistochemical study. Oral Oncol 2001;37:461-7.

25. Gandaglia G, Briganti A, Gontero P, et al. The role of chronic prostatic inflammation in the pathogenesis and progression of benign prostatic hyperplasia $(\mathrm{BPH})$. BJU Int 2013;112:432-41.

26. Chughtai B, Forde JC, Thomas DD, et al. Benign prostatic hyperplasia. Nat Rev Dis Primers 2016;2:16031.

27. Cheon SY, Jin BR, Kim HJ, et al. Oleanolic Acid Ameliorates Benign Prostatic Hyperplasia by Regulating PCNA-Dependent Cell Cycle Progression In Vivo and In Vitro. J Nat Prod 2020;83:1183-9.

28. Zhong W, Peng J, He H, et al. Ki-67 and PCNA expression in prostate cancer and benign prostatic hyperplasia. Clin Invest Med 2008;31:E8-E15.

29. Sampson N, Madersbacher S, Berger P. Pathophysiology and therapy of benign prostatic hyperplasia. Wien Klin Wochenschr 2008;120:390-401.

30. Mizokami A, Koh E, Izumi K, et al. Prostate cancer stromal cells and LNCaP cells coordinately activate the androgen receptor through synthesis of testosterone and dihydrotestosterone from dehydroepiandrosterone. Endocr Relat Cancer 2009;16:1139-55.

31. Park BK, Kim CW, Kwon JE, et al. Effects of Lespedeza Cuneata aqueous extract on testosterone-induced prostatic hyperplasia. Pharm Biol 2019;57:90-8.

32. Zhang J, Zhang $M$, Tang J, et al. Animal models of benign 
prostatic hyperplasia. Prostate Cancer Prostatic Dis 2021;24:49-57.

33. Kim EH, Brockman JA, Andriole GL. The use of 5-alpha reductase inhibitors in the treatment of benign prostatic hyperplasia. Asian J Urol 2018;5:28-32.

34. Aggarwal S, Thareja S, Verma A, et al. An overview on 5alpha-reductase inhibitors. Steroids 2010;75:109-53.

35. Motofei IG, Rowland DL, Tampa M, et al. Finasteride and androgenic alopecia; from therapeutic options to medical implications. J Dermatolog Treat 2020;31:415-21.

36. Morris CA, Duparc S, Borghini-Fuhrer I, et al. Review of the clinical pharmacokinetics of artesunate and its active metabolite dihydroartemisinin following intravenous,

Cite this article as: Zhang B, Chen X, Gan Y, Li BS, Wang KN, He Y. Dihydroartemisinin attenuates benign prostatic hyperplasia in rats by inhibiting prostatic epithelial cell proliferation. Ann Transl Med 2021;9(15):1246. doi: 10.21037/ atm-21-3296 intramuscular, oral or rectal administration. Malar J 2011;10:263.

37. Wang Y, Wang Y, You F, et al. Novel use for old drugs: The emerging role of artemisinin and its derivatives in fibrosis. Pharmacol Res 2020;157:104829.

38. Lei Z, Yang Y, Liu S, et al. Dihydroartemisinin ameliorates dextran sulfate sodium induced inflammatory bowel diseases in mice. Bioorg Chem 2020;100:103915.

39. Gao Y, Cui M, Zhong S, et al. Dihydroartemisinin ameliorates LPS-induced neuroinflammation by inhibiting the PI3K/AKT pathway. Metab Brain Dis 2020;35:661-72.

(English Language Editor: J. Teoh) 